\title{
PAISAGEM NATURAL E CONSTRUÍDA DA REGIÃO DE IMIGRAÇÃO DO SUL DO ESTADO DE SANTA CATARINA
}

\author{
NATURAL AND CONSTRUCTED LANDSCAPE OF THE REGION OF IMMIGRATION OF THE \\ SOUTH OF THE STATE OF SANTA CATARINA
}

\author{
SANTIAGO, Alina G. \\ Arquiteta e Urbanista, professora do programa PósARQ - UFSC, Florianópolis/ SC, \\ e-mail: alina@arq.ufsc.br.
}

\section{LUCA, Virgínia Gomes de}

Arquiteta e Urbanista, mestranda do programa PósARQ - UFSC, Florianópolis/ SC, e-mail:vgdeluca@yahoo.com.br

\section{RESUMO}

Estado de Santa Catarina possui um patrimônio que não encontra similares em todo o mundo. Trata-se das casas dos imigrantes que se deslocaram para cá, oriundos de diversas partes da Europa, com predominância de alemães, italianos, ucranianos, poloneses, entre outros. Estes imigrantes estabeleceram-se em regiões praticamente intocadas, localizadas no interior do Estado e fragilmente ligadas aos núcleos luso brasileiros já instalados no litoral.

Assim, desenvolveram-se as chamadas "ilhas culturais", que formam até nossos dias, contextos culturais praticamente inalterados e de inestimável valor patrimonial. Dialetos, técnicas agrárias, estórias, festas, hábitos alimentares, carpintaria e arquitetura, em geral, os "modos de fazer" são algumas das expressões vivas deste contexto, guardando elementos que muitas vezes já não existem em seus países de origem.

Estas ocorrências existem em espaços geográficos perfeitamente delimitados, emoldurados por paisagem natural e cultural, o que torna a referida "Região da Imigração" absolutamente excepcional no cenário nacional.

Atualmente essas áreas, que até então guardavam o legado cultural do imigrante, vêm passando por transformações que colocam em risco este patrimônio. $\bigcirc$ abandono da atividade agrária pelo pequeno produtor, a expansão dos perímetros urbanos dos centros próximos e a falta de perspectiva de crescimento econômico para a população levam os habitantes destas regiões a abandonarem suas propriedades ou a transformá-las radicalmente, a fim de adaptá-las aos conceitos atuais de conforto e modernidade.

\section{Palavras-chave: Imigração italiana, paisagem e patrimônio cultural.}

\begin{abstract}
The State of Santa Catarina possesss a patrimony that does not find similars in the whole world. One is about the houses of the immigrants who if had dislocated for here, deriving of diverse parts of the Europe, with predominance of Germans, Italians, ucranianos, Poles, among others. These immigrants had established themselves in regions practically intocadas, located in the interior of the State and fragilmente on to the Brazilian nuclei luso already installed in the coast.

Thus, the calls had been developed "cultural islands", that they form until our days, practically unchanged cultural contexts and of inestimable patrimonial value. Dialects, agrarian, estórias techniques, alimentary parties, habits, carpentry and architecture, in general, the "ways to make" are some of the alive expressions of this context, keeping elements that many times already do not exist in its native countries.

These occurrences exist in perfectly delimited geographic spaces, framed for natural and cultural landscape, what it becomes the cited "Region of absolutely bonanza Immigration" in the national scene.

Currently these areas, that until then kept the cultural legacy of the immigrant, come passing for transformations that place in risk this patrimony. The abandonment of the agrarian activity for the small producer, the expansion of the urban perimeters of the centers next and the lack to perspective of economic growth for the population
\end{abstract}


takes the inhabitants of these regions to abandon its properties or to transform them radically, in order to adapt them it the current concepts of comfort and modernity.

Key words: Italian immigration, landscape and cultural patrimony.

\section{Introdução}

Dentre as diversas etnias que compõem a população dos municípios do sul do Estado, a cultura de origem italiana se sobressai por apresentar maior expressão cultural, seja pelo número de núcleos quanto pelos testemunhos deixados pelos primeiros colonizadores. A cultura italiana deixou traços na arquitetura civil e religiosa, na indumentária, na música, nas danças e na culinária. Entre os recursos culturais, a região dispõe de um rico patrimônio pouco explorado, onde destacam-se a importância dos acervos de interesse histórico-cultural que representam os municípios de Urussanga e Nova Veneza.

Nos últimos anos, o interesse nacional pela preservação dos conjuntos históricos da imigração Européia em Santa Catarina tem crescido. A maioria das áreas fundadas pelos imigrantes germânicos e italianos ainda mantém um grande número de edificações construídas durante o final do século XIX e início do XX, caracterizadas por uma arquitetura de notável qualidade construtiva e métodos próprios trazidos pelos imigrantes. A arquitetura da região reflete a experiência e habilidade dos construtores que vieram, a diversidade étnica e a maneira como os imigrantes se adaptaram ao novo ambiente, usando conhecimentos de gerações e fontes locais de matéria prima. A evidência destes traços culturais estão claros nas inúmeras edificações existentes na região e únicas no contexto nacional.

O mínimo de manutenção e intervenção, nos últimos tempos, aliada a evidente necessidade de uma postura nacional de preservação, conservação e restauração resultam na necessidade premente da sua proteção como patrimônio nacional, visando preservar a autenticidade e integridade da arquitetura de imigração no sul do Brasil.

\section{Contextos gerais da imigração}

Em meados do século XIX, as áreas desocupadas do sul do Brasil e o crescimento da lavoura de café atraíram a mão-de-obra estrangeira, européia em maior número, devido principalmente às transformações sócio-econômicas que estavam ocorrendo naquele continente.

As maiores ondas imigratórias para o Brasil foram patrocinadas pelo Governo a partir da segunda metade do século XIX. O objetivo era trazer trabalhadores para substituir os escravos na agricultura e a executar tarefas necessárias à industrialização e ao desenvolvimento da economia. O movimento cresce a partir das décadas de 1870 e 1880 e se estende até quase a Segunda Guerra Mundial, em sua maioria pelos imigrantes europeus que estavam à procura de melhores condições de vida e de trabalho.

'No entanto, essa política imigratória teve o seu maior crescimento a partir de meados do século XIX. Naquele momento, três fatores de fundamental importância aconteciam no Brasil: a expansão cafeeira no Vale do Rio Paraíba, em São Paulo; o movimento para o fim do regime de escravidão negra e a necessidade imperiosa de se colonizar as terras incultas do país, principalmente as terras do sul, a fim, inclusive, de resguardá-las de invasões espanholas' (BALDIN, 1999, p. 30)

As primeiras experiências na substituição da força de trabalho escravo por imigrantes europeus começam a partir de 1819 e se intensifica na segunda metade do século XIX com a expansão 
cafeeira na Região Sudeste do país e pela necessidade de mão de obra provocada pela abolição do tráfico em 1850. Além disso, havia também a necessidade de ocupar o território, que limitava-se principalmente à faixa litorânea e a possibilidade de desenvolvimento econômico das áreas do interior.

Depois que os grandes fazendeiros de café contratam estrangeiros para trabalhar em suas terras, os Governos das Provinciais da região seguem o exemplo da iniciativa privada e desenvolvem programas de incentivo à vinda de trabalhadores de outros países, levando o Império a formular uma política oficial de imigração. Representantes do imperador brasileiro atuam em companhias internacionais de colonização sediadas em diversas cidades européias. Além da preocupação em obter mão-de-obra para a agricultura, há também o interesse de atrair a população branca para o país a fim de reduzir proporcionalmente o número de negros e mestiços no Brasil.

O Governo estimulou à imigração, sobretudo financiando as viagens, mantendo coloniais sob sua proteção e incentivando a imigração estrangeira para as províncias do sul do país, que se tornam estratégicas depois da Guerra do Paraguai. Neste caso, o objetivo é mais o de povoar áreas de densidade demográfica muito baixas do que o de substituir a mão-de-obra escrava. A colonização foi o grande fator de desenvolvimento para as Províncias do Sul do Brasil - dos atuais Estados do Paraná, Santa Catarina e Rio Grande do Sul.

Associado a estas questões estava o ponto de vista do imigrante cuja perspectiva de enriquecimento com fruto no trabalho, a possibilidade de adquirir lotes de terra, à grande propaganda promovida pelas sociedades colonizadoras e as promessas de infra-estrutura inicial garantida (pagamentos, utensílios agrícolas, sementes e colheita fácil) justificavam seu interesse.

Especificamente no caso do Estado de Santa Catarina, a ocupação a partir do século XVII, deu-se por diferentes etnias. Assim, o povoamento vicentista, açoriano e a colonização alemã, italiana e polonesa foram os principais grupos que contribuíram para a formação de culturas regionais. Os movimentos migratórios dos colonos de origem alemã e italiana foram em número as duas maiores forças da imigração européia no território catarinense. As outras etnias como polonesa, portuguesa e africana foram em números sensivelmente menores.

\section{O sul do estado}

O Sul do Estado de Santa Catarina era, até as últimas décadas do século XIX, coberto por matas virgens com exceção de poucas vilas situadas no litoral. A grande fertilidade do seu solo e a necessidade de ocupar as regiões de fronteira promoveu o interesse do Governo Geral da Província em povoá-la.

No sul do Estado, no triângulo entre o rio Braço do Norte, ao norte, o Rio Araranguá, ao sul e a Serra a oeste, encontra-se a parte colonizada em que prevalece o elemento italiano. A Bacia do Rio Tubarão sendo possuidora de terras de grande fertilidade carecia de mão-de-obra agrícola que pudesse explorá-las. Tal iniciativa coube ao Presidente da Província de Santa Catarina Alfredo D'Escragnolle Taunay, que justificou junto ao Governo Imperial as reais possibilidades que proporcionaria para a Província de Santa Catarina a criação de núcleos coloniais. Desembarcados em Laguna, os colonos eram transportados pelo Rio Tubarão até Morrinhos e de lá até Pedras Grandes, para onde seguiam a pé com seus pertences em carros de boi até onde havia estradas.

Desta forma, novas terras foram sendo demarcadas e novos núcleos de origem italiana foram se formando com levas de famílias passando por Azambuja, a mais antiga das colônias oficiais do sul - atualmente distrito do município de Pedras Grandes - localizado no Vale do Rio Tubarão. Criciúma e Nova Veneza datam de 1880 e 1891 respectivamente, sendo esta última uma colônia particular administrada pela Companhia Metropolitana. 
Entre as diversas Companhias Colonizadoras, estava a Companhia Metropolitana, que assumiu o compromisso de introduzir um milhão de habitantes. No sul a Companhia fundou a colônia de Nova Veneza, que em 1906 era a única que ainda existia e cuja imigração acabou no fim de 1893. Com a colonização de Nova Veneza terminou a imigração italiana no Estado.

\section{A paisagem natural e construída}

A região sul do Estado de Santa Catarina, pela quantidade de imigrantes italianos que recebeu, configura-se como uma verdadeira região de cultura ítalo-brasileira. As tradições populares se manifestam ainda hoje de forma intensa. É nesta região que se encontra a mais forte manifestação da arquitetura rural da ltália setentrional, ainda hoje preservada nas antigas construções e parte das construções novas que mantém algumas referências formais e espaciais tipicamente italianas. Cidades como Laguna, Tubarão e demais vilas litorâneas da região influenciaram a arquitetura produzida pelos primeiros imigrantes.

Os antigos núcleos criados no sul do Estado de Santa Catarina como Azambuja, Laguna, Criciúma, Orleans, Siderópolis pertenceram a diferentes Companhias Colonizadoras de diferentes épocas. A diferença cronológica no processo de ocupação da região foi suficiente para que se criassem núcleos de comportamento diferenciados. Um exemplo é Urussanga, que continuou recebendo imigrantes logo após a unificação da ltália, ainda muito ligados à economia agrícola das províncias de Beluno e Treviso (ambas pertencentes à região de Vêneto). Por outro lado, o núcleo de Nova Veneza, que foi colonizado quinze anos mais tarde ainda recebia imigrantes, os quais já faziam parte de uma nova Itália que começava a industrializar-se. Estes últimos eram também de províncias diferentes das regiões de Vêneto, Lombardia, Trentino, Friuli e Emiglia Romagna. $\bigcirc$ significativo número de imigrantes italianos nessa região fez com que a mesma se identificasse como uma verdadeira região de cultura da Itália setentrional. '

Segundo Baldessar:

A maior parte dos imigrantes do sul de Santa Catarina procediam de Vêneto onde a região, em sua extensão é montanhosa e pedregosa, pouco fértil onde o trabalho de agricultura é muito difícil.

$\mathrm{Na}$, realidade, Azambuja, Pedras Grandes, Urussanga, Siderópolis (Nova Beluno), Treviso, Jordão, boa parte de Nova Veneza são regiões montanhosas, ainda que suas montanhas não sejam tão pedregosas e íngremes como as de Vêneto (BALDESSAR, 1991, p. 70).

O assentamento no Vale do Rio Tubarão apresentou grande prosperidade econômica em função das férteis terras disponíveis, o que permitiu a especialização de edificações rurais de grande porte e com referências claras da arquitetura da ltália setentrional.

As primeiras casas eram improvisadas, com telhado de palha e o fechamento era dos mais diversos, podendo ser de pau-a-pique. Mas assim que era possível, os imigrantes construía sua casa permanente, com os conhecimentos técnicos trazidos da Itália e utilizando os materiais encontrados no próprio terreno

'Era o problema número um a resolver (a casa residencial). A primeira foi a casa improvisada. Depois de ter algum abrigo improvisado, o imigrante começava a instalar-se um pouco melhor.

Geralmente era escolhido um ponto nas proximidades do curso d'água e, se possível em terreno descendente, para ter um porão nos fundos, pensando na adega para vinhos. Nesses casos os porões eram construídos em paredes de pedra. Nisto os imigrantes eram especialistas, verdadeiros 
artistas, pelas práticas em sua Pátria-mãe. Houve quem construísse casas inteiras em pedra trabalhadas de forma impecável.

Para o telhado utilizava-se madeira roliça, mais fina e as achas de içara, que também chamavam simplesmente 'ripas'.

A madeira grossa para a armação geralmente era falquejada com machado, para dar-lhe forma quadrada. Isto era feito lá no mato onde a madeira era cortada, porque seria mais leve para transportá-la'(BALDESSAR, 1991, p. 71 e 72).

Os conjuntos são compostos por residências, cozinha, moinhos e detalhes como cantina no porão construída em pedra, telhado em duas águas com aproveitamento do sótão (geralmente pouca altura, para guardar e secar grãos e cereais), pequenas janelas alinhadas e cimalhas em pedra. Outras características importantes são as cantinas cavadas no próprio terreno unidades de produção do tipo 'caseiro' (vinícolas, alambiques de cachaça, embutidos, etc.), a cozinha separada do corpo central da casa, além de varandas e balcões ornamentados com lambrequins de madeira. ${ }^{2}$

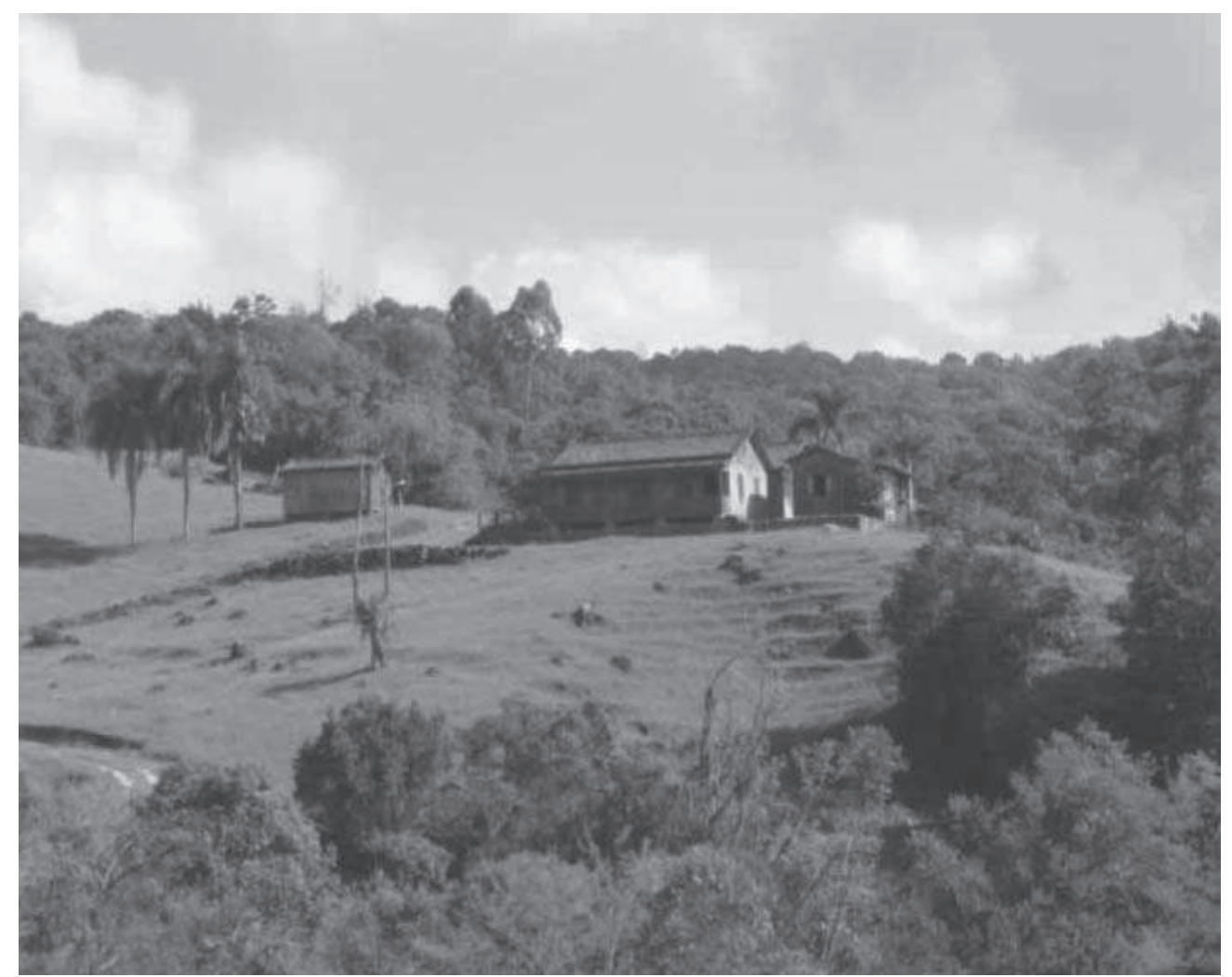

Foto 1: Propriedade de Luiza Sander (localidade rio América Baixo - Urussanga/ SC)

A implantação do conjunto de edificações no lote segue a prática de ocupação livre e separada por funções: casa de dormir, cozinha, estala, paiol, galinheiro, tendo sempre como construção principal a casa de dormir, que receberá um tratamento especial. (FLORIANO, 1988, p. 7)

Crédito: Virgínia Gomes de Luca

'Do emprego habilidoso dos materiais e técnicas construtivas, resulta notável expressão plástica, dentro de uma simplicidade que se manifesta, na tendência simétrica, quer de maneira austera, limitando ao essencial os elementos construtivos, quer através de ornamentação discreta.

Em relação à arquitetura rural do norte italiano da época da imigração, guarda uma relação - e não transposição - inequívoca sob o ponto de vista construtivo, porém, quanto à organização dos espaços verifica-se um anta- 
gonismo: na Itália, geralmente todas as atividades aglomeravam-se numa só edificação, em aldeias rurais e no Brasil, a cada atividade corresponde a sua própria construção, no próprio lote de cada colono. Além disso, no Brasil, em função da abundância de madeira, criam-se processos nativos para este material' (POSENATO, 1983, p. 74).

Ainda que houvesse fertilidade do solo e a estrada de ferro Dona Teresa Cristina, construída em 1880, que permitia o escoamento da produção, alguns colonos passaram, a partir de 1918, a ocupar-se com a extração do carvão e a fixar-se nos núcleos de exploração do subsolo. Devido ao acelerado crescimento econômico, alguns núcleos coloniais como Criciúma, passaram a funcionar como pólo regional. Outros núcleos, apesar do desenvolvimento, não sofreram transformações radicais, preservando assim, parte do acervo das edificações urbanas construídas.

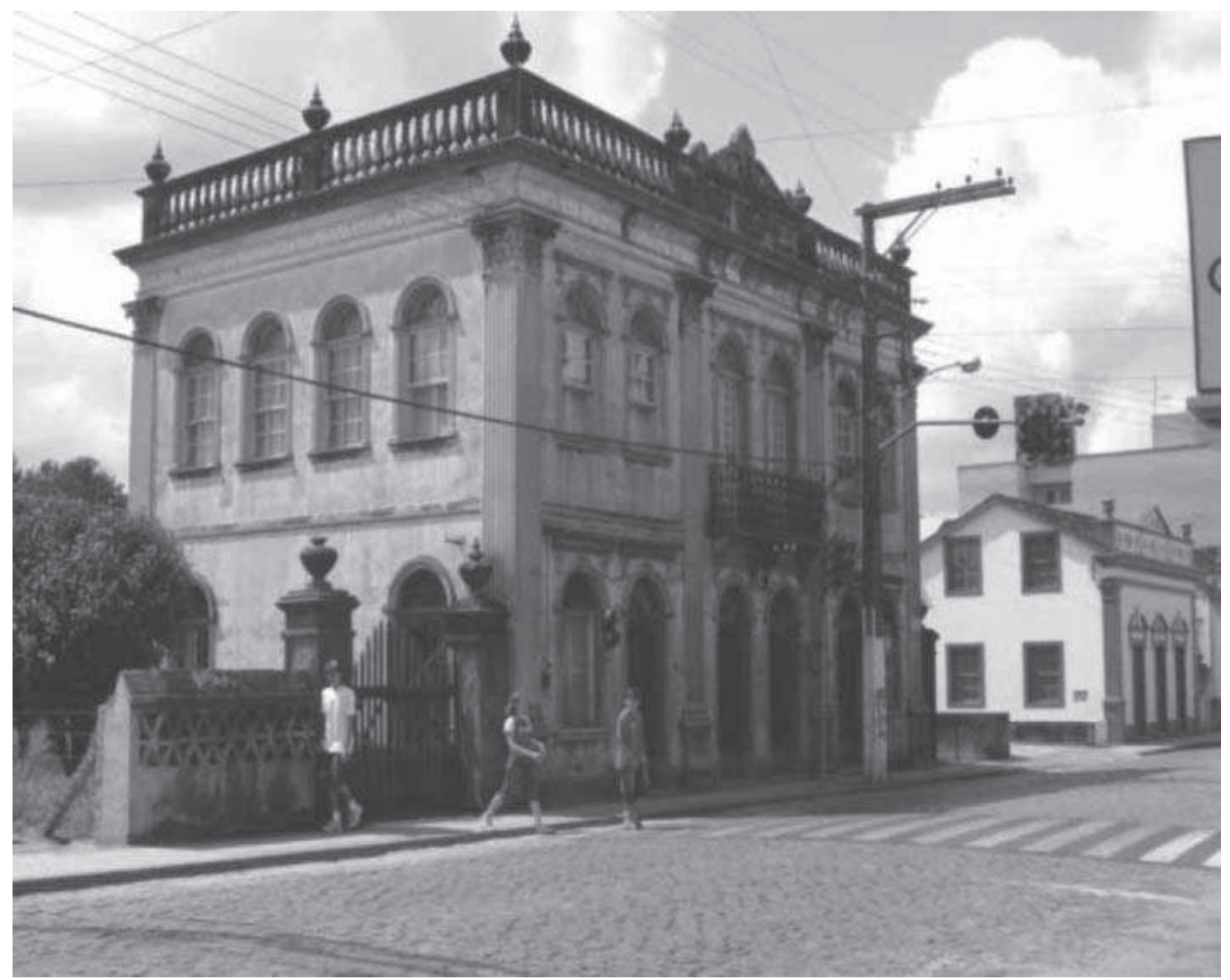

Foto 2: Sobrado Nichelle - 1907 (Centro - Urussanga/ SC). Edificação atualmente sem uso, é a mais rica em detalhes construtivos do centro da cidade de Urussanga.

Crédito: Virgínia Gomes de Luca

'O sul do Estado, dentre todos os núcleos coloniais apresentará maior urbanização, devido a exploração do carvão, gerando grande êxodo na área rural, principalmente na cidade de Criciúma, onde será espacializado um tecido urbano totalmente novo, no qual maior parte dos edifícios construídos já referenciam num estatuto funcionalista.

A área rural estagnada preservará parte de seus monumentos coloniais em pedra e madeira, tanto os conjuntos residenciais, quanto os moinhos e as primeiras indústrias artesanais.

Em toda a grande área colonial percebe-se, desde a área rural até os pequenos povoados e periferia urbana dos grandes centros, uma visualidade referenciada na tradição construtiva no trabalho de taipa de pedra e no uso da madeira, configurando em toda a região durante o decorrer deste século, uma homogeneidade construtiva' (FLORIANO, 1988, p. 15) 


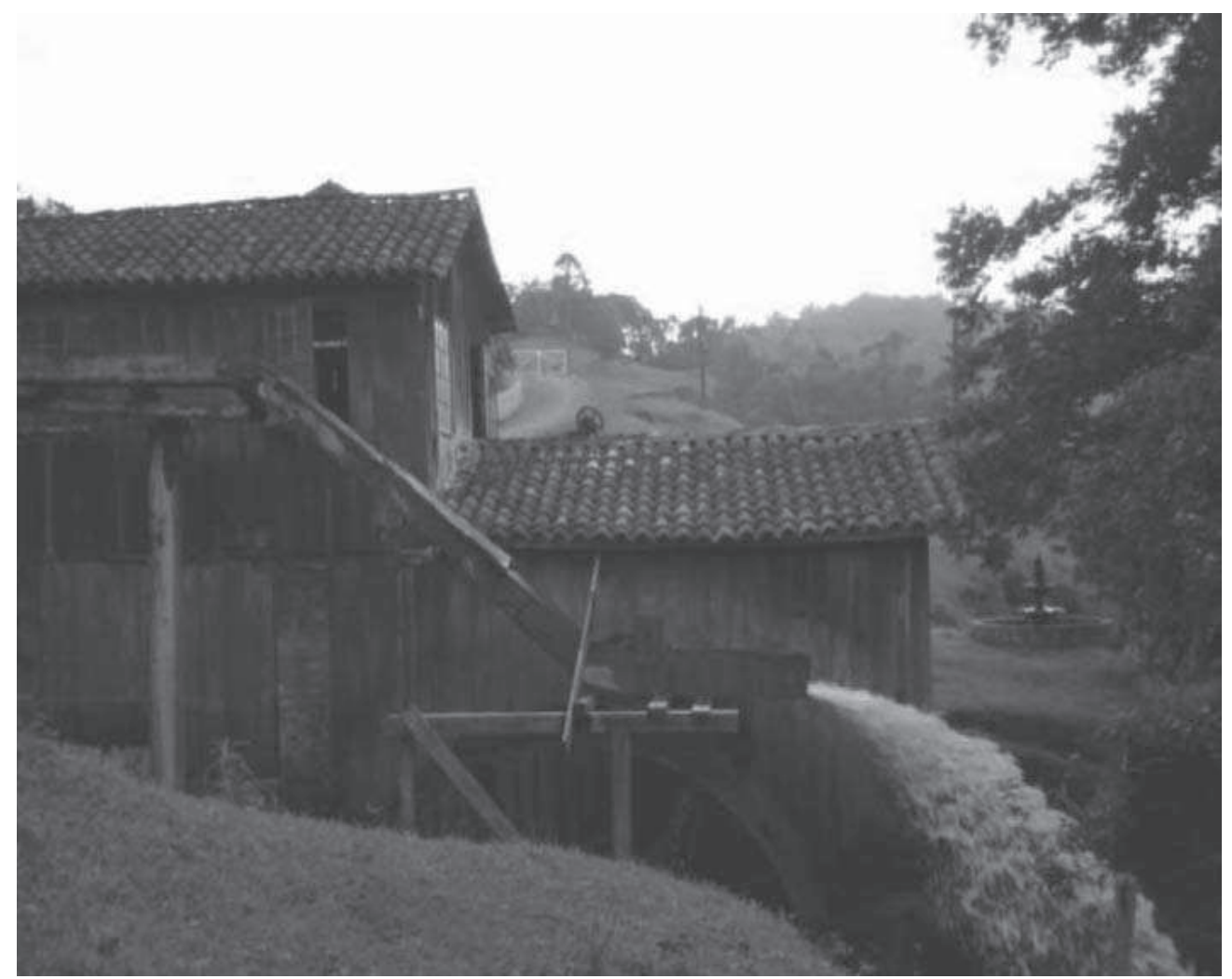

Foto 3: Propriedade rural da família Bez Fontana - 1901 (localidade rio América Baixo Urussanga/ SC). Principal exemplar em madeira da região, conserva em perfeito estado o sobrado residencial de madeira, a cozinha separada do corpo principal em alvenaria de tijolos, e unidades de produção como serraria, atafona, marcenaria e descascador de arroz movido à roda d'água.

Crédito: Virgínia Gomes de Luca

O patrimônio artístico e arquitetônico é seguramente mais rico nas edificações religiosas com suas pinturas internas e esculturas em madeira como altares, púlpitos e principalmente imagens sacras. A Igreja Católica, desde o início, sempre teve um papel muito importante nestas comunidades e isso constata ainda hoje através de inúmeras manifestações religiosas. ${ }^{3}$

acervo arquitetônico da imigração está disposto ao longo de um caminho que espelha um processo histórico de ocupação do território catarinense ao sul, a partir da segunda metade do século XIX. Situadas na paisagem aos pés da Serra Geral, estas edificações destacam-se por sua volumetria e relação com seu entorno. São testemunhos de cultura e tradições trazidas ao Brasil por imigrantes de diversas partes do mundo. A grande falta de recurso fez com que eles utilizassem o material disponível na região adaptando-os a suas técnicas construtivas. Desta forma, o sul de Santa Catarina conta com autênticos exemplares em madeira, pedra e tijolos.

\section{Considerações finais}

O presente ensaio buscou de forma sucinta descrever um breve histórico da imigração italiana no sul do Estado de Santa Catarina. A região conta com exemplares da arquitetura da imigração ainda bem caracterizados enquanto conjunto inserido em paisagens ainda preservadas. Esta herança cultural representa um período importante no acervo do contexto arquitetônico brasileiro, tanto pelas características plásticas quanto pelas técnicas construtivas e de uso dos materiais.

Nesse sentido, é necessário sensibilizar a população a as autoridades para que estes documentos vivos da História, que revelam através das gerações os conceitos, as técnicas e até mesmo os usos e costumes de famílias que abandonaram sua terra natal e aqui vieram refazer sua história. A valorização da arquitetura vernacular do imigrante italiano cria uma consciência de 
preservação desse legado arquitetônico e o salva do processo de destruição, ao mesmo tempo em que fortalece os laços comuns das populações locais.

O despertar das consciências sobre o valor deste ciclo conseguiria evitar a perda total deste acervo. Contudo, e mais importante, cabe preservar os aspectos positivos da cultura de imigração italiana: o zelo pela arquitetura advirá então como conseqüência (POSENATO, 1983, p. 573).

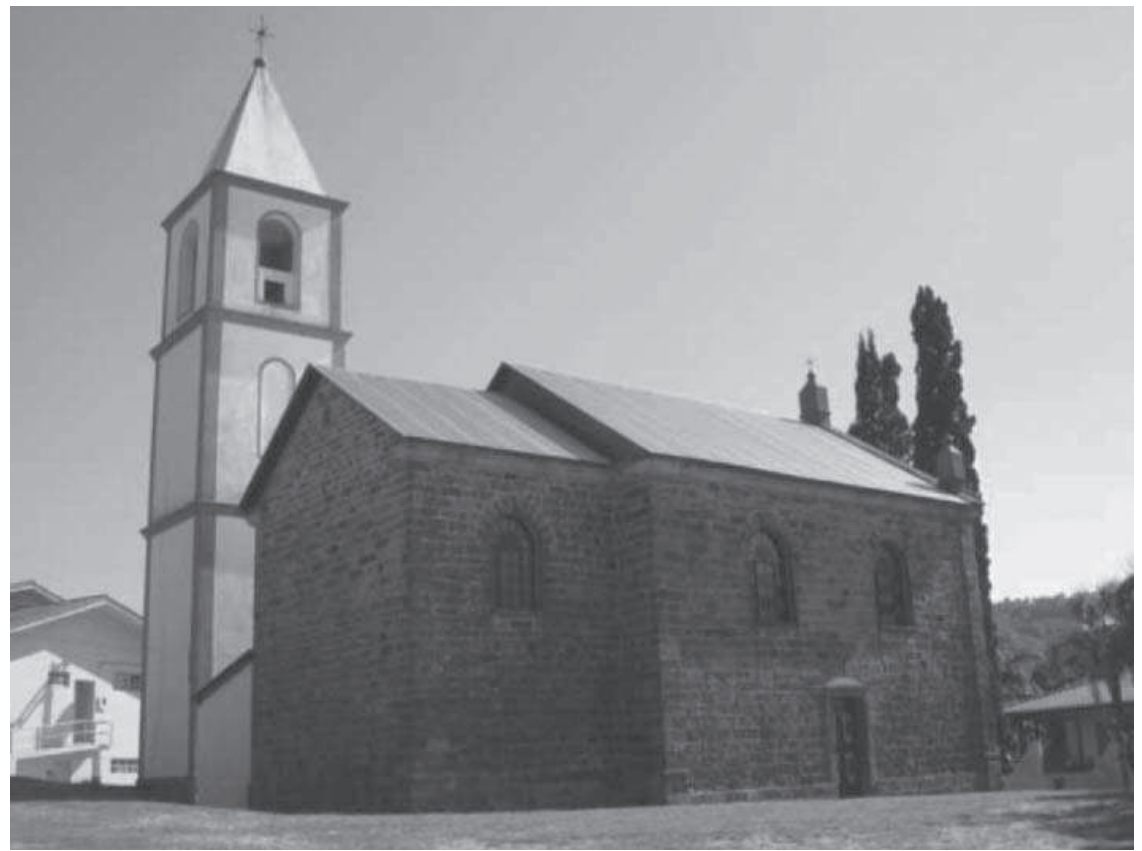

Foto 4: Igreja São Gervásio e São Protásio - 1912 (localidade de rio Maior -

Urussanga/SC). Excepcional exemplar da arquitetura religiosa italiana, construída em pedra arenito. Planta constituída por capela-mor e nave principal. Possui campanário, construído em 1940 em substituição ao de madeira, separado do corpo da igreja

Crtédito: Virgínia Gomes de Luca

\section{Notas}

(1) Textos Técnicos da Fundação Catarinense de Cultura.

(2) Textos Técnicos da Fundação Catarinense de Cultura.

(3) Textos Técnicos da Fundação Catarinense de Cultura.

\section{Bibliografia}

SOUZA, Celso de Oliveira. Museu ao ar livre de Orleans: Oficinas do saber: apoio didático para trabalhar educação patrimonial. Orléans: FEBAVE, 2002.

LEMOS, Carlos A. C. O que é patrimônio histórico? São Paulo: Brasiliense, 1981.

DALL'ALBA, João Leonir. Imigração italiana em Santa Catarina. Florianópolis: Lunardelli, 1983.

POSENATO, Júlio. Arquitetura italiana no Rio Grande do Sul. Porto Alegre: EST/ EDUCS, 1983.

BALDIN, Nelma. Tão forte quanto a vontade, história da imigração italiana no Brasil: Os vênteos em Santa Catarina. Florianópolis: Insular/Ed. Da UFSC, 1999.

$216 \quad 1988$

MEMÓRIA E EDUCAÇÃO. Rio de Janeiro: IBPC/Departamento de Promoção/Paço Imperial, 1992.

TEXTOS TÉCNICOS da Diretoria do Patrimônio Cultural da Fundação Catarinense de Cultura. 